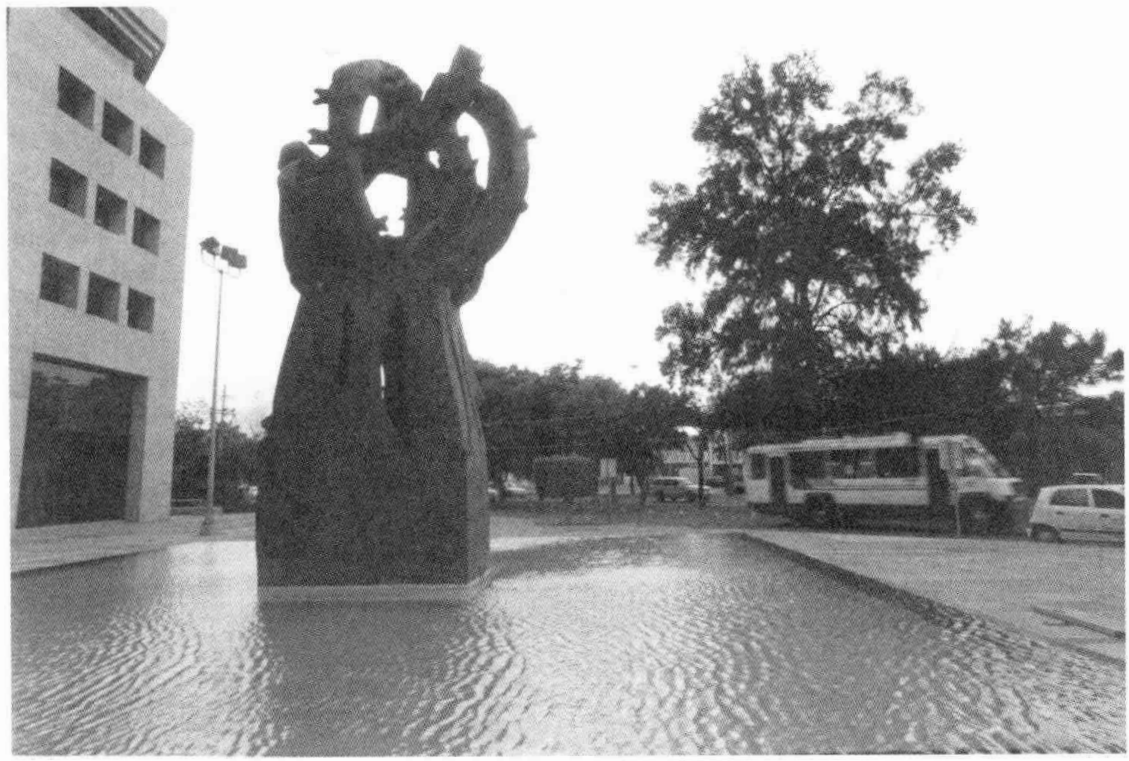




\section{Alfredo Avila y María José Garrido Asperó}

Alfredo Ávila es doctor en Historia por la Universidad Nacional Autónoma de México, investigador de tiempo completo en el Instituto de Investigaciones Históricas y profesor de la Facultad de Filosofía y Letras de la misma Universidad. Es autor de En nombre de la nación, Taurus, México, 2002, y Para la libertad. Los republicanos en tiempos del imperio, UNAM, México, 2004.

María José Garrido Asperó es maestra y candidata a doctora en Historia por la Universidad Nacional Autónoma de México. Es profesora investigadora en el Instituto Mora. Especialista en historia cultural y política de comienzos del siglo XIX mexicano, ha publicado varios artículos en revistas como Estudios de Historia Moderna y Contemporánea de México, y Secuencia.

\section{Resumen}

Después de medio siglo de haber aparecido por primera vez La revolución de independencia de Luis Villoro sigue siendo una lectura muy difundida. Este artículo se propone evaluar la vigencia de dicha obra, más allá de los asertos que han sido superados por estudios monográficos recientes. Considera que el libro de Villoro fue pionero en muchas interpretaciones que hoy son muy aceptadas por los especialistas en el tema y que, hasta la fecha, es el único que da un sentido al proceso ideológico de la revolución de independencia. Sugiere, por último, una nueva apreciación del papel de las concepciones sobre la temporalidad que Villoro resalta como un punto de partida para futuras investigaciones de historia intelectual en torno al pensamiento político de las primeras décadas del siglo XIX mexicano.

Palabras clave:

Luis Villoro, independencia de México, clases sociales, actitud histórica, ideología, temporalidad.

\begin{abstract}
Half a century after it was first published, Luis Villoro's La revolución de independencia continues to be widely read. This article attempts to assess the relevance of this work, beyond the assertations surpassed by recent monographs. It considers that Villoro's book pioneered many interpretations that are now largely accepted by specialists in the area and that to date, he is the only person to have lent meaning to the ideological process of the independence revolution. It ends by suggesting a reappraisal of the role of conceptions in temporality, highlighted by Villoro as a starting point for future intellectual history research on the political thought of the early decades of the Mexican 19th century.
\end{abstract}

\section{Key words:}

Luis Villoro, Mexican independence, social classes, historical attitude, ideology, temporality.

Fecha de recepción:

noviembre de 2004

Fecha de aceptación: abril de 2005 


\title{
Temporalidad e independencia. El proceso ideológico de Luis Villoro, medio siglo después
}

\author{
Alfredo Avila \\ María José Garrido Asperó*
}

$\square$ n 1953 apareció el libro de Luis Villoro La revolución de independencia, primero de una serie de volúmenes planeada por Antonio Castro Leal para conmemorar el bicentenario del natalicio de Miguel Hidalgo. Todavía puede hallarse una reimpresión de la tercera edición de esta obra en las librerías, y una síntesis de la misma se reproduce en la Versión 2000 de la muy consultada Historia general de México. ${ }^{1}$ Esto quiere decir que, pese a los

* Este trabajo forma parte de nuestras actividades en el proyecto La Independencia de México: Temas e Interpretaciones Recientes, que se lleva a cabo en el Instituto de Investigaciones Históricas de la UNAM con apoyo de la Dirección General de Asuntos del Personal Académico (PAPIIT IN402602).

${ }^{1}$ Hay que hacer notar que la Versión 2000 de la Historia general de México tiene cambios importantes respecto a las ediciones anteriores de la misma obra, pero mantuvo, entre otras, la misma colaboración de Villoro, "Revolución", 2000. No pretendemos señalar que ese capítulo se hubiera incluido porque los editores lo consideraran vigente, pero el hecho de que aparezca en una obra de tal difusión e importancia indica que todavía será consultado por un amplio público. En cuanto a la edición que todavía circula en las librerías es de un gran tiraje, tres mil ejemplares por reimpresión: Villoro, Proceso, 1999. La primera edición llevaba el título de La revolución de independencia. Ensayo de interpretación bistórica, Villoro, Revolución, 1953. resultados de investigaciones recientes que han cambiado la manera como concebimos el proceso emancipador mexicano, la interpretación propuesta por Villoro hace más de medio siglo sigue siendo conocida por miles de lectores, desde los que sólo sienten interés por este tipo de temas hasta estudiantes y profesionales de la historia. No pretendemos responder por qué los editores del Consejo Nacional para la Cultura y las Artes o del Centro de Estudios Históricos de El Colegio de México han seguido reimprimiendo un trabajo de tal antigüedad, pues desconocemos sus motivos. Sin duda, cuando La revolución de independencia apareció por primera vez, ofreció una versión muy novedosa acerca del desarrollo intelectual durante el proceso de emancipación, aunque, a más de medio siglo, merece la pena preguntarse cuál es la vigencia de una interpretación realizada hace tanto tiempo.

La revolución de independencia fue escrita en un momento de especial florecimiento intelectual en México. En la Facultad de Filosofía y Letras de la Universidad Nacional Autónoma de México se reunía un grupo de filósofos, alumnos de José Gaos, conocido como Hiperión. Cercanos al existencialismo francés y al raciovitalismo alemán, los hiperiónidas proponían que la 
única manera como los mexicanos podían hacer un aporte significativo a la filosofía era desde su originalidad, desde las peculiares circunstancias mexicana y latinoamericana. Esto no significaba que su pensamiento buscara definir el sentido de "lo mexicano", como algunos hicieron después. Los problemas que debían abordar eran los mismos que los de los pensadores de otras naciones. La única diferencia radicaba en que las respuestas aportadas en México tomarían en cuenta las características de este país y de los otros de América Latina, como no se cansaría de insistir Leopoldo Zea. Por esta razón, se hacía urgente una reflexión sobre la historia mexicana, un ejercicio de autoconocimiento que varios de los miembros de aquel grupo, como Luis Villoro, llevaron a cabo. ${ }^{2}$ No obstante, esta incursión al pasado se hacía con un sentido diferente al de los tradicionales estudios históricos, lo cual tal vez explicaría la fría recepción de algunas de sus obras entre los historiadores. El objetivo, como el de toda filosofía, era estudiar al hombre, pero en condiciones históricas concretas.

La dirección intelectual de José Gaos fue determinante para que los hiperiónidas $y$, en especial, Luis Villoro, se acercaran al historicismo para pensar desde esa perspectiva al ser humano; pero también los historiadores profesionales habían venido dando a la prensa los excelentes resultados de sus investigaciones que, asimismo por influencia del maestro español, se habían dirigido hacia la historia de las ideas. No pocos de esos estudios estaban dedicados a las luces del siglo XVIII novohispano, lo cual contribuiría para una mejor comprensión de las ideas del periodo de la in-

2 Villoro, "Génesis", 1950, y Garrido, "Caminos", en prensa. dependencia. Trabajos como el de Monelisa Lina Pérez-Marchand habían sido impulsados por las traducciones publicadas en el Fondo de Cultura Económica de obras fundamentales como la de Ernst Cassirer. ${ }^{3} \mathrm{~A}$ todo lo anterior, Villoro sumó algunas de las interpretaciones del materialismo histórico, pues le permitían explicar las diferencias ideológicas entre grupos y clases sociales, aunque, según él mismo afirmaría, de una manera incompleta. De hecho, como veremos después, la noción de ideología de Villoro debe más a la sociología de Karl Mannheim que al marxismo. Así, con este cúmulo de ideas y de opciones metodológicas (cuyo resultado no dejaría, por lo mismo, de ser un tanto ecléctico), Villoro se propuso estudiar, por encargo de Leopoldo Zea, el proceso ideológico de la revolución de independencia de México.

La revolución de independencia se escribió, sobre todo, a partir de la lectura de documentos producidos en el periodo de la emancipación, con muy poco apoyo de bibliografía. El resultado fue, hasta cierto punto, una interpretación ingenua, novedosa y ajena a muchos de los prejuicios que por entonces había acerca de los padres de la patria y de sus hechos. Los libros citados en la primera edición incluyen a los clásicos de Lucas Alamán, Carlos María de Bustamante y Servando Teresa de Mier, entre otros, a los que se agregaron unos cuantos historiadores del siglo $\mathrm{Xx}$, como Marius André, Cecile Jane, Alfonso Teja Zabre, Silvio Zavala y Luis González. ${ }^{4}$

\footnotetext{
${ }^{3}$ Pérez-Marchand, Dos, 1945, y Cassirer, Filosofía, 1943.

${ }^{4}$ André, Fin, 1922; Jane, Libertad, 1942; Teja, Morelos, 1946; Zavala, Historia, 1940, y González, "Optimismo", 1985.
} 
Consultó los documentos de la época en las maravillosas colecciones documentales realizadas por Juan E. Hernández y Dávalos y Genaro García. No cuenta, por lo tanto, con investigación en archivos, aunque, sobre todo al final, se citan varios impresos que tuvo que consultar en algún fondo reservado, tal vez el de la Biblioteca Nacional.

El libro mereció pocas reseñas. Una muy elogiosa de Luis González y González ya señalaba la novedad de la interpretación propuesta por Villoro. Hugh Hamill apuntaba que una de las grandes virtudes de la obra era presentar la "Revolución ligada al pasado y al futuro, y no aparece tan sólo como una serie de episodios militares amontonados juntos de una manera descuidada." Por su parte, Catalina Sierra Casasús se percató de que no era obra de un historiador sino de un filósofo, que había empleado una "armazón conceptual" con la cual dividía a la sociedad en clases, "error" que se prestaba a "graves confusiones". En realidad, Sierra se oponía a las generalizaciones explicativas y abogaba por un estudio más detenido y riguroso de los datos, aunque reconocía que "dada su importancia, la interpretación que de nuestra independencia hace el autor constituirá en adelante una lectura obligada para el estudioso y para el simple interesado en esta época clave de nuestra historia". ${ }^{5}$ Poco después aparecieron algunos trabajos de desigual importancia para el tema de las ideas de la independencia, como el de Francisco López Cámara, La génesis de la conciencia liberal en México; el de Jesús Reyes

5 Hamill, "Reseña", 1954; González, "Nuevos", 1954; Sierra, "Nuevos", 1954. Una muy elogiosa reseña a la segunda edición la hizo Krauze, "Luis", 1970.
Heroles, El liberalismo mexicano. Los orígenes, y el colectivo Presencia de Rousseau, que ninguna mención hicieron de La revolución de independencia. ${ }^{6}$ En cambio, Villoro incluyó buena parte de las interpretaciones de estos autores (y del fundamental José Miranda ${ }^{7}$ ) en una colaboración para el libro Estudios de bistoria de la filosofía en Mé$x i c 0^{8}$ y en la segunda edición de su libro, aparecido en 1967 con el título definitivo de El proceso ideológico de la revolución de independencia. En 1976, cuando publicó "La revolución de independencia" para la Historia general de México, de El Colegio de México, ya había incorporado algunos de los resultados de Enrique Florescano, Precios del maíz y crisis agricolas en México, y de David Brading, Mineros y comerciantes en el México borbónico, ${ }^{9}$ libros que sirvieron también para hacer algunos ajustes a la tercera y definitiva edición, en especial en los capítulos primero y último.

\section{LAS INTERPRETACIONES SOBRE \\ LA INDEPENDENCIA MEXICANA y LA OBRA DE VILLORO}

El tema de la emancipación y de las corrientes ideológicas durante las primeras décadas del siglo XIX no es nada novedoso. $\mathrm{La}$ independencia era uno de los temas favoritos de los historiadores mexicanos, al menos hasta antes de la revolución de 1910. El que el proceso revolucionario del siglo $\mathrm{Xx}$ se convirtiera, después, en una verdadera obsesión para la historiografía,

\footnotetext{
${ }^{6}$ López, Génesis, 1954; Reyes, Liberalismo, 1957, y Presencia, 1962.

${ }^{7}$ Miranda, Ideas, 1952.

${ }^{8}$ Villoro, "Corrientes", 1963.

9 Florescano, Praxios, 1969, y Brading, Minems, 1975.
} 
no eliminó los estudios sobre el proceso que llevó al país a figurar entre las naciones soberanas del mundo. Para la época en la que Luis Villoro escribió su fundamental obra, había, como él mismo señaló, al menos dos interpretaciones bien diferenciadas sobre las tradiciones intelectuales que actuaron como motor de las emancipaciones, a saber, aquella que acusaba al pensamiento tradicional español, de raigambre escolástica, y la que valoraba elementos liberales y modernos en las ideas de los criollos. La primera consideraba que la independencia fue una reacción conservadora, primero frente a la ruptura del pacto de dominación debida a la usurpación napoleónica en 1808 y, después, ante el liberalismo impulsado por la Constitución de 1812 y, en especial, por los radicales del Trienio. Si bien importante, ésta no era la opción más popular entre los historiadores. De hecho, la interpretación que gozaba de mejor aceptación era la opuesta. A riesgo de simplificar en exceso, según buena parte de la historiografía, la opresión de la monarquía española sobre el pueblo mexicano (cuya existencia antes de la independencia no se cuestionaba) ocasionó un enorme descontento popular $\mathrm{y}$ ansias de libertad en aquellos que hallaron, en las ideas de la ilustración y de la revolución francesa, un medio de romper con el yugo europeo.

Esta manera de entender el papel de las ideas durante el proceso de independencia había sido promovida por el liberalismo triunfante de finales del siglo XIX. Al menos, podemos apreciarla desde el tomo que Julio Zárate escribió para el monumental México a través de los siglos. La socialización de esta interpretación por medio de la educación pública y del discurso oficial, le dio gran empuje. Incluso después de la caída del régimen porfiriano, se mantuvo vigente en historiadores que no compartían el credo liberal que la había impulsado. No fueron pocos los marxistas que, si bien introdujeron algunas consideraciones sobre la lucha de clases (que enemistaría a las clases populares del virreinato con los criollos, sus presuntos redentores, según la versión liberal), terminarían aceptando que, por momentos, hubo coincidencias de objetivos entre las aspiraciones del pueblo y los ideales de algunos dirigentes ilustrados, como Miguel Hidalgo. Sin embargo, desde este punto de vista, la alianza entre clases no podría durar mucho y, al final, la consumación de la independencia fue reaccionaria y respondió a los intereses de los criollos, representados por Agustín de Iturbide, ajenos por completo a las necesidades del pueblo, de ahí que el conflicto se mantuviera por todavía largos años. ${ }^{10}$ Dada la fuerza de esta interpretación y la falta de trabajos monográficos (a mediados del siglo $\mathrm{xx}$ ) sobre las condiciones económicas, sociales y culturales de grupos subalternos a finales de la colonia, no resulta extraño que se siguiera reproduciendo la misma versión sobre las aspiraciones libertarias ciel pueblo en no pocos estudios serios, incluso en la misma Revolución de independencia.

Después de medio siglo, éste es el punto más débil de la propuesta de la obra de Villoro, sobre todo a la luz de los excelentes trabajos de autores como Peter Guardino, Claudia Guarisco, Virginia Guedea, Brian Hamnett, John Tutino y, en especial, Eric Van Young, acerca de los comportamientos políticos de los diferentes

${ }^{10}$ Véase, entre otros, Teja, Historia, 1934, pp. 31-36. Para lo del movimiento trigarante como reaccionario, pp. 41 y 87. 
grupos sociales que, todavía hasta hace pocos años, se englobaban en el término muy general de "pueblo". ${ }^{11}$ Hoy sabemos, gracias a trabajos como los de los autores citados, que hubo indígenas que no titubearon en defender el orden español y que muchas comunidades se vieron beneficiadas al poder contar con milicias para contener a los insurgentes y por el establecimiento de los ayuntamientos constitucionales impulsados por la Constitución de Cádiz. Hemos empezado a entender que las razones de los rancheros y los sectores medios rurales del Bajío y de la región de Guadalajara para unirse al movimiento encabezado por Miguel Hidalgo eran más complejas que los supuestos anhelos de libertad contra la opresión española. El milenarismo y otros aspectos de la ideología popular han sido estudiados con detenimiento y se discute la posibilidad de que los pueblos impulsaran un proyecto nacional. En suma, la generalización sobre las "clases populares" y sus objetivos durante el proceso de independencia no ha podido sostenerse frente a los estudios monográficos recientes, que muestran una gran diversidad.

No obstante, Villoro consiguió separarse, en parte, de la interpretación liberal sobre la independencia, la cual insistía en que los americanos habían sido los promotores más importantes de la emancipación debido a que estaban desplazados por los españoles peninsulares. Ésta sería la razón principal por la que los criollos hicieron alianza con las clases populares en contra del dominio ibérico. Por supuesto, esta versión no podía explicar por qué muchos

${ }^{11}$ Guardino, Peasants, 1996; Guarisco, Indios, 2003; Guedea, "Indios", 1987; Hamnett, Raices, 1990; Tutino, Insurrection, 1986, y Van Young, Otber, 2001. criollos no compartieron el odio a los gachupines ni fueron partidarios de la insurgencia. En $L a$ revolución de independencia, Villoro propuso que, después de todo, el lugar de nacimiento no era tan importante para determinar qué partido se tomaría. De mayor importancia eran la clase, los vínculos y los intereses. Con un mínimo de bibliografía especializada sobre la cual apoyarse, Villoro propuso la existencia de cuatro clases con características y posiciones políticas diferenciadas a comienzos del siglo XIX. La "clase europea" incluía a distintos grupos sociales, como la alta burocracia, el clero catedralicio, los cuadros superiores del ejército y los grandes mineros y comerciantes. Por lo tanto, estaba compuesta en su mayoría por europeos, y su posición estaba garantizada por la dependencia de la metrópoli. Una segunda clase dominante (llamada en la primera edición "eurocriolla", aunque suprimió ese nombre en las siguientes) integraría a propietarios ligados al sector interno de la economía, clero y cuadros medios del ejército, en su mayoría, pero no únicamente, criollos. La "clase media o criolla", desligada de la metrópoli, por lo general no era propietaria. Estaba constituida por pequeños comerciantes, curas más bien pobres, administradores y, sobre todo, letrados. Por último, las clases populares, la mayor parte de la población, sería integrada por indios, trabajadores mineros y de obrajes, castas, negros y un largo etcétera.

De nuevo es cierto que los estudios monográficos posteriores han hecho muy vulnerable la generalización propuesta por Villoro, pero sigue siendo muy útil para una explicación global de la independencia, como han señalado varios autores. Timothy E. Anna, por ejemplo, pudo apreciar que, al final, La revolución de inde- 
pendencia se adecuaba a la interpretación liberal tradicional, sobre todo por dividir de un modo tan tajante a las "clases propietarias" de la "clase media". Esta división, como bien notó Anna, tenía por objeto mostrar que en 1821 triunfó una posición contrarrevolucionaria, combatida después por los liberales de los siguientes años. El mismo autor de La caída del gobierno español en la ciudad de México resaltó cómo los estudios de Doris Ladd y de David Brading ponían en problemas las agrupaciones sugeridas por Villoro, pero reconocía que era una clasificación social útil, al grado de que para su propio estudio la tomó como base, haciendo sólo unos cuantos ajustes:

En vez de las cuatro clases que propuso Villoro (administradores y comerciantes, propietarios y militares, clase media, clase obrera), pueden proponerse cuatro divisiones ligeramente modificadas: administrativa real y elite extranjera, elite local o plutócratas, pequeña burguesía, y pobres. ${ }^{12}$

Como puede apreciarse, en el fondo, la propuesta de Anna no es tan diferente de la de La revolución de independencia. En todo caso, pone de manifiesto que las críticas hechas a la interpretación de Villoro también podrían hacerse a la propia. Estudios posteriores, como los de Brian Hamnett, han venido a precisar con mayor cuidado los componentes de los grupos sociales a finales del periodo virreinal. Este autor británico también distinguió a la "elite mexicana o residente" compuesta en su mayoría por comerciantes-inversionistas, y una "burguesía provincial" formada por abogados, clérigos, intelectuales y mé-

${ }^{12}$ Anna, Caída, 1981, p. 33. dicos, entre otros. De la misma forma que en su momento hicieron Villoro y Anna, reconoció que ninguna categoría es homogénea, en especial por la diversidad regional. ${ }^{13}$ En esto, creemos, Hamnett dio un paso más allá de lo que lo habían hecho los otros autores, pero en sustancia conviene recordar que sería Villoro el primero en proponer el esquema de cuatro grupos sociales para explicar los conflictos de la independencia de una forma mejor que la de recurrir al enfrentamiento criollogachupín. Cada una de esas clases actuaría según su propia experiencia. Más adelante nos referiremos a las "actitudes históricas" y propuestas ideológicas de cada una de ellas; de momento sólo reiteramos que, hacia mediados del siglo $\mathrm{xx}$, esta interpretación fue muy novedosa y todavía, con los ajustes que requiera, sigue siendo útil.

No obstante el trabajo de Villoro, como lo señaló de un modo claro a partir de la segunda edición, era un trabajo de historia de las ideas. No resulta extraño, por lo mismo, que se inscribiera en un grupo de obras revisionistas que aparecieron, por cierto, hacia la conmemoración del bicentenario del nacimiento de Miguel Hidalgo. De hecho, entre las principales aportaciones hubo muchas que contrariaron la versión tradicional que apuntaba al pensamiento ilustrado-liberal como motor de la independencia. Por supuesto, buena parte de los trabajos que se publicaron por esos años estaban impulsados por afanes patrióticos, algo muy explicable por el tema del cual se trata, por lo que no se negaba que, en última instancia, los ideales de los jefes insurgentes, y en especial del conmemorado, eran libertarios, pero se ponía más atención a su formación reli-

${ }^{13}$ Hamnett, Raices, 1990, pp. 37 y ss. 
giosa. ${ }^{14}$ Ya desde 1945, Gabriel Méndez Plancarte había resaltado la carrera académica del profesor y rector del Colegio de San Nicolás, en especial las propuestas hechas en su célebre Disertación sobre el verdadero método de estudiar Teología Escolástica. Es verdad que el análisis propuesto por Méndez Plancarte iba dirigido a probar la gran valía intelectual de Hidalgo, presentándolo como un reformador, pero se hacía evidente que sus propuestas se mantenían en los límites de la teología y que ninguna de sus posibles inflúencias podía ser acusada de "enciclopedista". ${ }^{15} \mathrm{La}$ renovación intelectual promovida en la Disertación hidalguina se reducía a promover una teología más positiva, cercana a las fuentes biblicas y patrísticas y a la historia. Otros autores recogerían esta interpretación. Sin negar la importancia de la ilustración, se precisaba que se trataba de una ilustración católica, en la que no aparecían los autores irreligiosos como referentes. Ernesto de la Torre se encargatía de resaltar la lectura de la Historia eclesiástica de Fleury, mientras que Juan A. Ortega y Medina valoraría la "conciencia cristiana" del cura de Dolores por encima de otras improbables filiaciones liberales. ${ }^{16}$

En resumen, la historiografía revisionista de mediados del siglo $\mathrm{xx}$ no negó

${ }^{14}$ Hernández, "Mundo", 1953.

${ }^{15}$ Méndez, Hidalgo, 2003.

16 Torre, "Hidalgo", 1953; Ortega y Medina, "Problema", 1952. Años después, Agustín Churruca Peláez extendería este tipo de consideraciones al más importante de los jefes de la insurgencia, José María Morelos. Reconocía, como hacía la historiografía tradicional, que las medidas sociales, políticas y económicas del Caudillo del Sur y de otros dirigentes del movimiento eran muestra clara de un pensamiento libertario; aunque éste no renegaba de sus orígenes cristianos: Churruca, Pensamiento, 1983. la importancia de la renovación que la ilustración promovió entre los pensadores novohispanos de finales del siglo XVIII y comienzos del XIX; pero la encuadró en una tradición hispánica que bien podía llegar a los humanistas del siglo de la conquista y a la Escuela de Salamanca, tanto en su versión dominica como en la jesuítica. El mismo Villoro continuaría esta labor de revisionismo, en especial al poner su atención en los saberes jurídicos de los letrados criollos de 1808. En La revolución de independencia demostró que (tal vez con la excepción del mercedario Melchor de Talamantes) las propuestas de los miembros del Ayuntamiento de la ciudad de México y de otros criollos como el oidor Jacobo de Villaurrutia debían poco al pensamiento revolucionario francés y mucho al derecho hispánico. Por su parte, el constitucionalismo histórico español de Melchor de Jovellanos, Martínez Marina y José María Blanco halló eco en el regiomontano Servando Teresa de Mier, quien desarrollaría la idea de la existencia de un estatuto de igualdad entre las Indias y la metrópoli, originado en un pacto entre los conquistadores y los reyes de Castilla en los albores del siglo XVI. ${ }^{1.7}$ Como ya había notado Edmundo O'Gorman, en la Historia de la revolución de Nueva España Mier argüiría que los diversos acontecimientos sucedidos desde 1808 en la metrópoli estaban rompiendo el pacto fundamental con los reinos indianos, lo cual les permitiría a éstos buscar una redefinición en la dependencia con Europa. En definitiva, los americanos no eran colonias de España sino súbditos de un monarca que, por cierto, se hallaba ausente del trono. ${ }^{18}$

${ }^{17}$ Villoro, Revolución, 1953, pp. 37-41.

${ }^{18}$ Mier, Escritos, 1945, y Fray, 1945. 
Luego de Villoro, no serían pocos los historiadores que continuaron la investigación sobre el pensamiento constitucionalista-histórico. Dảvid Brading insistiría en que la Carta Magna promovida por Servando Teresa de Mier se convertiría en uno de los argumentos más sólidos en toda América para promover la independencia, como mostró Bolívar en su Carta de Jamaica. En tiempos más recientes, François-Xavier Guerra ha resaltado también el pactismo como una forma de pensamiento político anterior al liberalismo, esgrimido por los criollos que, ante la crisis iniciada en 1808, propusieron la autonomía para sus territorios. ${ }^{19}$ Villoro había notado que este pensamiento podía proporcionar argumentos para alcanzar la independencia, pero sólo para "dirigirse y administrarse según las leyes fundamentales del reino," 20 pues eran legalistas: buscaban la libertad amparados en el orden vigente y no, como harían los insurgentes después, instaurar un nuevo orden en la libertad. ${ }^{21}$ Este legalismo fue después reconocido por autores como Virginia Guedea para asegurar que, en el fondo, los miembros del Ayuntamiento de México en 1808 no buscaban la erección de una nación soberana independiente de España sino sólo autogobierno. ${ }^{22}$ Vale la pena señalar que, en los años recientes, la tesis de

${ }^{19}$ Esta vertiente de pensamiento seguiría siendo trabajada por el mismo O'Gorman y por David Brading: Brading, Orígenes, 1972; Mier, Ideario, [1978]. Acerca del pactismo americano, Guerra, Modernidad, 1993, pp. 169-175.

${ }^{20}$ Villoro, Revolución, 1953, p. 42.

${ }^{21}$ El tema ya lo había expuesto Villoro en un ensayo antecedente de su libro: "Hidalgo", 1952.

${ }^{22}$ Guedea, Busca, 1992, pp. 15-65. En el mismo sentido, véase Guedea, "Criollos", 1964. Un caso excepcional en 1808 fue Melchor de Talamantes, algo la búsqueda de la autonomía (en vez de una independencia revolucionaria) ha sido quizá la más influyente en los estudios sobre el proceso de emancipación. Obras como las de Jaime E. Rodríguez O., por citar sólo al autor más destacado dentro de esa corriente interpretativa, han puesto en primer plano los empeños de las elites urbanas (entre los que vale la pena destacar a los letrados) para obtener ventajas de autogobierno dentro de la gran revolución hispánica. ${ }^{23}$

Hacia mediados del siglo Xx, la historiografía estaba dejando de lado la interpretación de que el liberalismo fue fuente e inspiración del movimiento independentista. La tradición católica, el saber jurídico y el constitucionalismo histórico habían sido más importantes y, en no pocas ocasiones, eran opuestos al liberalismo. El libro de Villoro, inscrito en ese revisionismo, contribuyó de un modo fundamental a esta crítica. $\mathrm{Ni}$ los promotores de la independencia en 1808 ni Miguel Hidalgo hubieran aceptado ser liberales. Bien al contrario, los primeros eran, en su mayoría, juristas que no se hallaban dispuestos a arriesgar el orden vigente, mientras el segundo se dejó envolver en el frenesí revolucionario de un modo más bien irresponsable. Sin embargo, Luis Villoro, el filósofo, no dejó pasar la oportunidad para hacer una reflexión sobre el "instantaneísmo". Tal vez el cura de Dolores no pensó en dar la soberanía al pueblo, como la in-

ya notado también por Villoro, como supo apreciarlo Torre, Constitución, 1978, p. 31.

${ }^{23}$ Queremos resaltar en especial a Rodríguez, "Transición", 1993; "Súbditos", 1997, y Rey, 2003; aunque la obra de este historiador es mucho más amplia y merecería, por sí, un estudio de su impacto en las interpretaciones del periodo emancipador. 


\section{SECUENCIA}

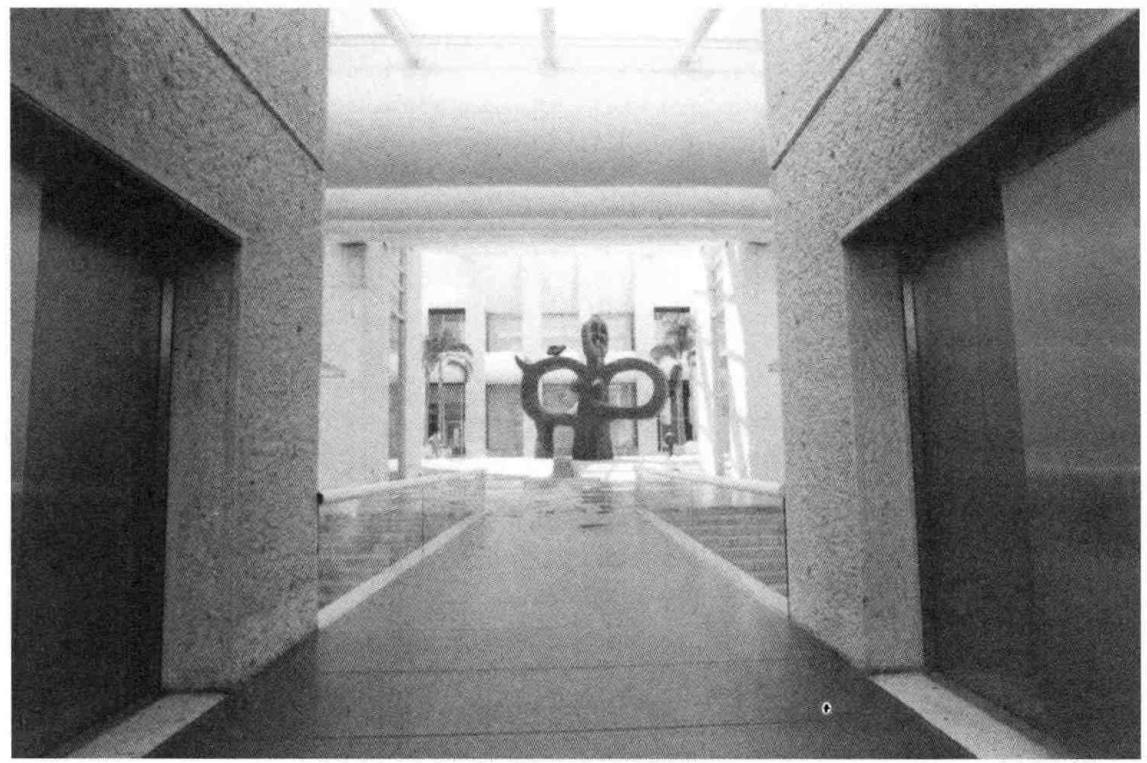


terpretación tradicional insiste, pero lo consiguió al destruir las bases del viejo orden y fundar en la libertad uno nuevo. ${ }^{24}$ Historiadores como Ernesto Lemoine retomarían la importancia de este señalamiento para, con una mayor información documental, comprender el "salto" dado por el conspirador para convertirse en rebelde. ${ }^{25}$ En todo caso quedó claro que Hidalgo no requirió la lectura de los revolucionarios de Francia para ser uno, ni que la insurgencia fuera liberal. Como es sabido, Mier no simpatizaba mucho con las Cortes gaditanas ni con la Constitución de 1812; mientras que algunos de los ideólogos más destacados de la insurgencia, como José María Cos, Andrés Quintana Roo y Carlos María de Bustamante, sirvieron a Villoro para ejemplificar "la persistencia de la concepción política tradicional" frente a las medidas revolucionarias impulsadas por los liberales españoles. ${ }^{26}$

$L$ a revolución de independencia fue uno de los primeros libros en señalar (después de que lo hiciera Lucas Alamán en su importante Historia de México) que si el liberalismo estuvo presente en el proceso independentista se debió, en buena medida, a las Cortes de Cádiz y a los diputados novohispanos que asistieron a la asamblea extraordinaria española. Así, ponderó las leyes y decretos gaditanos en el desarrollo posterior del liberalismo mexicano. Quizá porque el autor era filósofo (y, por lo mismo, no se hallaba tan inmerso en la tradición historiográfica mexicana, la cual contenía una buena carga de prejuicios), leyó con cierta inocencia los documentos impresos que tuvo a su alcance, lo que le permitió

\footnotetext{
${ }^{24}$ Villoro, "Hidalgo", 1952.

${ }^{25}$ Lemoine, Morelos, 1990, p. 180.

${ }^{26}$ Villoro, Revolución, 1953, pp. 91-99.
}

concluir que, en efecto, gran parte de los elementos modernos del Decreto constitucional sancionado en Apatzingán, máxima expresión de los ideales insurgentes, se debían a la Carta sancionada en Cádiz, algo que después comprobaría Anna Macías. ${ }^{27}$ La modernidad liberal, como diría tiempo después Guerra, se desarrolló antes en España que en América, donde el pactismo siguió vigente largo tiempo. ${ }^{28}$

No pretendemos afirmar que Villoro fue el fundador de la interpretación, tan aceptada en la actualidad por la historiografía dedicada al tema, que pondera al liberalismo gaditano como fuente del mexicano. Desde otra trinchera (también ajena a la tradición historiográfica mexicana), Nettie Lee Benson se había percatado de esto. ${ }^{29}$ Pero, además, el mismo Villoro abjuró su interpretación, debido a que por los mismos años en que apareció La revolución de independencia fueron publicados varios trabajos (éstos sí herederos de las interpretaciones liberales decimonónicas) que reafirmaron el ascendiente revolucionario francés de nuestro proceso de independencia. Me refiero en especial a los libros de Francisco López Cámara, La génesis de la conciencia liberal (un estudio teleológico del pensamiento dieciochesco); José Miranda, Las ideas y las instituciones politicas mexicanas

${ }^{27}$ Ibid., pp. 99-107; Macías, “Autores”, 1971, y en especial Macías, Génesis, 1973, pp. 118-151.

${ }^{28}$ Guerra, Modernidad, 1993, pp. 319-350.

29 Benson, Diputación, 1955; Benson, Mexico, 1966. Vale la pena señalar que algunos de los primeros trabajos de Benson hubieran podido ser conocidos por Villoro para la primera edición de La resolución. Quiza todavía tenían poca difusión a comienzos de la década de 1950, pero, en todo caso, para las reediciones del Proceso ya eran lo suficientemente reconocidos. De cualquier forma, al parecer no tuvieron influjo alguno en la interpretación de Villoro. 
(un excelente estudio que "se cae", como bien ha señalado Roberto Breña, al momento de describir las ideas libertarias de los insurgentes), y Jesús Reyes Heroles, Presencia de Rousseau y, sobre todo, El liberalismo mexicano. Resulta muy curioso que a partir de la segunda edición de la obra villoriana se "corrigiera" lo que desde nuestro punto de vista fue un acierto, por la versión más tradicional de la ascendencia revolucionaria francesa sobre los autores de la Constitución de Apatzingán. ${ }^{30}$

En resumen, La revolución de independencia compartió algunas características de la interpretación liberal tradicional del proceso emancipador, como la generalización sobre los ideales del "pueblo", pero también se inscribía en la revisión académica que algunos historiadores estaban iniciando y que descubría tradiciones diferentes al liberalismo en las ideas de los principales pensadores criollos. Incluso, en la primera edición, apuntó la necesidad de estudiar el liberalismo español como fuente del mexicano. Con todo y la importancia de estas aportaciones, como veremos adelante, la principal es otra.

ACTITUDES HISTÓRICAS

Y TEMPORALIDAD

Según afirmaría después, Villoro se interesó en la independencia de México por ser un momento en el que el país negó su pasado y se proyectó a un futuro propio. ${ }^{31}$ Este proceso dio inicio tras las abdicacio-

${ }^{30}$ Villoro, Proceso, 1999, pp. 118-120. Anna Macías confirmaría el primer aserto de Villoro sobre las fuentes intelectuales de la Constitución de Apatzingán. Sobre Miranda véase Breña, "Ideología", 2004, p. 23.

${ }^{31}$ Garrido, "Caminos", en prensa, p. 212. nes de Bayona, consideradas ilegítimas por la mayor parte de los españoles americanos. Desde ese momento, el orden político dejaría de ser uno impuesto por la tradición o la naturaleza de las cosas. Incluso aquellos que querían conservar a toda costa las instituciones de la monarquía absoluta debieron tomar medidas innovadoras para conseguir sus objetivos. Luis Villoro llamó a esto "actitud histórica" y es el medio que empleó para estudiar las ideologías de cada uno de los grupos y clases de finales del virreinato. Al parecer (pues no lo hizo de un modo explícito), Villoro partió de la propuesta de Karl Mannheim acerca de que la estructura mental de cada grupo puede entenderse "si nos enfocamos a comprender su concepción del tiempo a la luz de sus esperanzas, anhelos y propósitos." 32

En La revolución de independencia se llama "actitud" a la disposición (favorable o en contra) de un grupo respecto de la sociedad existente. Desde el punto de vista de Villoro, dichas actitudes son predispuestas (aunque no condicionadas de un modo determinante) por la situación económica y social de cada clase. ${ }^{33} \mathrm{La}$ posición de los individuos y grupos en el proceso de producción y reproducción de la realidad constituye el punto de inicio de las actitudes históricas. La dinámica de la historia, según Villoro, "sólo da comienzo con la respuesta del individuo o grupo social a la situación en que se encuentra". Así, la ideología de cada clase se explica por su actitud ante la realidad y la historia. ${ }^{3.4}$

\footnotetext{
${ }^{32}$ Mannheim, Ideology, 1985, p. 209. Villoro empleó la versión española publicada por el FCE, 1941.

${ }^{33}$ Villoro, Revolución, 1953, p. 10.

${ }^{34}$ Ibid., 1953, p. 8. Luis Villoro define el término ideología como "el conjunto de creencias de un grupo
} 
Implica, por lo tanto, la adhesión a ciertos valores imaginarios: la interpretación del pasado, la valoración del presente y la proyección del futuro. La temporalidad es el eje conductor de la interpretación de $L a$ revolución de independencia; procura responder a cómo cada grupo o clase social de finales del virreinato imaginaba el futuro del país.

De nuevo Villoro se apoyó en Mannheim. En Ideología y utopía se sugiere la posibilidad de que las posiciones políticas de la intelligentsia (un término, también recuperado por Villoro, teferido a una clase desvinculada en cierta medida de las clases sociales) se pueden explicar por el lugar que se asigna en el tiempo al mejor estado de cosas social. Los liberales pensarían que la sociedad más perfecta se halla en el futuro y hacia allá habría que encaminarse; los radicales no serían muy diferentes, pero exigirían la actualización de ese futuro. Por el contrario, los conservadores asegurarían que el mejor estado posible es el presente y, por lo mismo, debía conservarse; y tampoco faltarían los utópicos que aseguraran que todo tiempo pasado fue mejor y, por lo tanto, habría que regresar a él. ${ }^{35}$ Estas posiciones políticas se hallarían presentes en todos los pensadores a partir del siglo XIX, si bien algunas ya pueden ser apreciadas desde antes. Tiempo

social; insuficientemente justificadas, que cumplen la función de promover el poder de ese grupo" ("El concepto de actitud y el condicionamiento social de las creencias" en Villoro, Concepto, 1985, p. 111) y como "forma de ocultamiento en que los intereses y preferencias propios de un grupo social se disfrazan, al hacerse pasar por intereses y valores universales" ("Del concepto de ideología" en Villoro, Concepto, 1985, p. 18).

${ }^{35}$ Mannheim, Ideology, 1985, pp. 153, 192-263. después, Hayden White recuperaría la interpretación de Mannheim para analizar, precisamente, las obras de los historiadores decimonónicos. ${ }^{36}$

A partir de la división propuesta por Villoro para los grupos o clases sociales novohispanos a comienzos del siglo XIX, delineó cuatro actitudes históricas durante la revolución de independencia: el "preterismo estático", el "preterismo dinámico", el "futurismo" y el "instantaneísmo". Estas actitudes se corresponderían, de modo respectivo, con "la clase dominante del grupo hegemónico" o "europea", con la clase "euro-criolla" (los "otros grupos" de la clase dominante, como la llamó a partir de la segunda edición), con la "clase media" y, por último, con la "clase trabajadora". Para la burocracia política, el alto clero, los cuadros superiores del ejército, los grandes propietarios mineros y los comerciantes, la sociedad era percibida de un modo estático. Su tiempo era el pasado, roto con la crisis de 1808. Por tal motivo se esforzaron en hacer que el presente y el futuro sólo fueran la continuación de lo anterior. Para ellos, la sociedad no estaba regulada por la "acción voluntaria y racional del pueblo ni de minorías selectas", sino que se hallaba dada. La prosperidad material y el auge cultural de Nueva España durante la segunda mitad del siglo XviII no indicaba, para esta clase, ninguna transformación posible, tan sólo exigía un orden administrativo eficaz: "La temporalidad de la sociedad no surge del futuro sino del pasado. El presente es sólo continuidad y persistencia de éste, que se prolonga en el advenir siguiendo su curso." 37

36 White, Metabistory, 1973, pp. 22-29.

37 Villoro, Revolución, 1953, p. 174, y Proceso, 1999 , p. 188. 
Por su parte, los propietarios vinculados con el sector interno de la economía, terratenientes, el clero y los cuadros medios del ejército entendían el acontecer histórico como una lenta transformación. No negaban la posibilidad de un futuro diferente, siempre y cuando estuviera arraigado en el pasado y se alcanzara sin convulsiones ni rupturas violentas. Para estos criollos privilegiados la independencia era deseable. Consideraban que con la separación de España podían eliminar las trabas impuestas por el régimen colonial. Estaban impregnados de ese optimismo que, como bien había señalado en 1946 el entonces estudiante Luis González, era compartido por la mayoría de los habitantes del virreinato, ocasionado por la abultada confianza en la riqueza del país. ${ }^{38}$ Tan sólo consideraban que la independencia no debía ser fruto de la "libertad" (es decir, de la decisión de los individuos y grupos sociales) sino de la "madurez" de una entidad, el virreinato, que al llegar a la mayoría de edad se emanciparía de su progenitora. El cambio debía ser resultado de transformaciones lentas que cumplieran en el presente y en el futuro los valores del pasado. La sociedad, aseguraba Villoro, no elegía otros valores, sino que cumplía y completaba los de la etapa colonial. La independencia sería así, para esta clase, el cumplimiento y persistencia del México colonial. ${ }^{39}$

La posición privilegiada de estos criollos hacía de ellos un grupo con una posición práctica ambigua: en ocasiones impugnó el régimen colonial, pero a la hora de la insurrección de 1810 no dudó en

${ }^{38}$ González, "Optimismo”, 1985.

39 Villoro, Revolución, 1953, pp. 193-195, y Proceso, 1999, pp. 208-211. apoyarlo. En cambio, la "clase media" se hallaba desligada de la metrópoli y su posición social no dependía de manera directa de los privilegios otorgados por la monarquía española. Desde su perspectiva, el auge económico del siglo XVIII en nada, o casi nada, la había favorecido. La posibilidad de beneficiarse de las riquezas del país, las reales y las imaginadas, se abría en el futuro, siempre y cuando se negara el pasado que la había marginado. La intelligentsia criolla, compuesta en su mayoría por letrados, transitó de un ideario fundado en la tradición jurídica española al liberalismo. En términos de Mannheim, abrazó primero una utopía, que pretendía hallar en el remoto (y ficticio) pasado una base para el futuro, para después convertirse en radical, al pretender actualizar, volver presente el futuro: retorno a los orígenes y negación del pasado inmediato. ${ }^{40}$

Más adelante volveremos sobre las actitudes históricas de la "clase media", pues ella será el personaje central de la obra que venimos comentando. Es menester, sin embargo, señalar cuál fue la posible actitud de la "clase trabajadora", en realidad un conjunto muy heterogéneo de grupos que compartían la misma situación de opresión por parte del régimen. A partir del movimiento de Miguel Hidalgo, Villoro concluyó que esta clase derogó el pasado (el orden impuesto), pero fue incapaz de proyectarse al futuro. Así, atrapada en un presente continuo, se envolvió en la guerra, en el "frenesî", en la vivencia del instante. ${ }^{41}$ En el único reconocimiento

\footnotetext{
${ }^{40}$ Villoro, Revolución, 1953, p. 99, y Proceso, 1999, p. 115.

${ }^{41}$ Villoro, Revolución, 1953, pp. 61-65, y Proceso, 1999, pp. 77-80.
} 
hecho por Villoro de la importante lectura de la obra de Mannheim, señaló la semejanza del pensamiento de las masas insurgentes con el de las que participaron en las guerras campesinas alemanas del siglo XVI o los anabaptistas, es decir, milenaristas e instintivamente igualitarios. ${ }^{42}$

El proceso descrito por Villoro está tejido con el desarrollo de estas cuatro posiciones ideológicas a partir de 1808 , si bien la conductora es la de la "clase media". Ante la crisis ocasionada por las abdicaciones de Bayona, los criollos del Ayuntamiento de la ciudad de México quisieron recuperar el pasado originario para fundar en él la organización social. De ahí su insistencia en remitirse a las leyes de Partida, a la imaginada Carta Magna, y a las leyes fundamentales del reino. No cuestionaban la legitimidad del orden legal sino que, antes bien, exigían su cumplimiento. Pretendían ser libres sobre el derecho vigente. Sin embargo, la "clase europea" impidió cualquier paso propuesto por los criollos. Para ella, la sociedad debía mantenerse inalterada. El pasado inmediato debía conservarse, aunque no lo haría por sí solo. Por eso, decidió actuar. El golpe de mano de septiembre de 1808 contra el virrey José de Iturrigaray y el Ayuntamiento capitalino fue la manera como los comerciantes y grandes privilegiados pretendieron mantener el orden, pero les fue contraproducente. El orden legal parecía, en efecto, el mismo, pero no era ya dado sino resultado de una acción arbitraria. La posibilidad de cambiar, con la propia actuación, el presente y el futuro, quedaba abierta. Los criollos se percataron de esto: p. 86.

${ }^{42}$ Villoro, Revolución, 1953, p. 70, y Proceso, 1999 ,
"La libertad no se funda en el derecho sino el derecho en la libertad." 43

El agravio del ofensor y, sobre todo, la incorporación de la clase trabajadora en el movimiento de independencia en 1810 condujeron a lo que Villoro llamó la "conversión" de los criollos. Si bien muchos independentistas mantuvieron el discurso lleno de referencias jurídicas y legales (la persistencia de la concepción política tradicional) e incluso opuesto al liberalismo impulsado en Cádiz por esos mismos años, surgió la tendencia de negar el orden colonial completo. La negación del pasado, según Villoro, condujo a la clase media a buscar un futuro que ninguna relación tuviera con la tradición española. De ahí la adopción de la república. En el Congreso de Chilpancingo puede percibirse el triunfo de esta actitud histórica y de la nueva concepción política. La clase media reunida en esta asamblea, al desconocer la organización política y social de la monarquía española, ya no fundaba la independencia en las antiguas leyes; por el contrario, construía a la nación sobre la noción de soberanía popular. Abolía, con ello, la constitución social de la colonia y elegía organizarse libremente de nuevo. ${ }^{44}$

La actitud histórica de la clase media se nos ha presentado en tres aspectos que se implican recíprocamente. Trinitaria unidad, es a la vez negación de la realidad, repetición del origen y elección de la posibilidad. Podemos llamarla por su nombre: conversión. Negación, repetición y elección son tres facetas con que aparece el mismo acto de conversión histórica, según se les considere referido a uno u

\footnotetext{
43 Villoro, Revolución, 1953, p. 52, y Priceso, 1999 , p. 67.

${ }^{44}$ Villoro, "Corrientes", 1963, p. 230.
} 
otro de los éxtasis temporales. En cuanto negación se refiere al pasado, o al presente como vestigio de éste; en cuanto repetición se refiere a sí mismo, es decir a la libertad que renueva las posibilidades históricas en el instante; en cuanto elección se refiere al futuro. ${ }^{45}$

El radicalismo del movimiento insurgente hizo que las clases privilegiadas unieran filas con la europea. Sin embargo, esto no significa que no favoreciera, en algún momento, la emancipación. Cuando parecía desvanecerse la amenaza de la rebelión popular fue el momento de los criollos privilegiados, quienes después de derrotar el movimiento de las clases media y trabajadora consumaron la independencia, siempre según Villoro, como una contrarrevolución. Toda vez que la actitud de los vencedores pretendía sólo acoplar el orden político al económico o, en otras palabras, beneficiarse de las riquezas de Nueva España sin compartirlas con la metrópoli, evitó en la medida de lo posible la transformación del orden antiguo y optó por una constitución moderada, respetuosa de la monarquía y del orden social tradicional, eliminó "las estipulaciones legislativas que se oponían a su desarrollo y otorgó algunas concesiones a la clase media y castas para evitar su descontento." 46

La caída del imperio encabezado por Agustín de Iturbide significó el asenso de la clase media al poder, pero el relato tejido por Villoro no terminó ahí: fue un triunfo incompleto. El último capítulo de la obra nos presenta la crítica del utopismo y la prolongación, a lo largo del siglo XIX,

45 Villoro, Revolución, 1953, p. 157, y Proceso, 1999 , p. 170.

${ }^{46}$ Villoro, Revolución, 1953, p. 185, y Proceso, 1999 , p. 200. del conflicto de la solución preterista (la conservadora, encabezada por Lucas Alamán) y la futurista (la liberal, representada por José María Luis Mora). Sin embargo, como señalamos antes, la protagonista de La revolución de independencia es, sin duda, la clase media. No sólo es así por el mayor número de palabras destinadas a ella, o por la estrategia narrativa que nos la presenta como una entidad en transformación (por medio de la conversión, mientras los demás grupos mantienen una misma actitud histórica) sino, sobre todo, porque ella es la única revolucionaria, y el tema del libro es la revolución. Si en el texto no se ve su victoria sobre la solución preterista de la clase dominante, de cualquier manera hay un ideologema implícito que supone la victoria de la clase media y de su proyecto revolucionario en la historia de México. ${ }^{47}$

\section{MEDio SIGLO DESPUÉS}

Luego de más de 50 años, resulta claro que buena parte de las interpretaciones propuestas por Villoro no se sostendrían a lá luz de nuevos datos. En especial, las investigaciones sobre los diversos grupos sociales que en la obra analizada se llamaban "clases trabajadoras", han venido a mostrar que el mundo de lo subalterno a finales del virreinato era mucho más complejo y menos homogéneo de lo que se imaginaba

47 Álvaro Matute denomina ideologema a un enunciado que expresa, en breve, un contenido ideológico, de alcance universal ("la historia es la historia de la lucha de clases", "el progreso es la ley de las sociedades") que, como bien señala, puede estar de moxlo implícito en un discurso, como fundamento del mismo. Matute, "Historia", 1997, pp. 7-8. 
a mediados del siglo Xx. No obstante, la caracterización realizada en $L a$ revolución de independencia para las clases sociales rompió con la vieja explicación de la guerra como un conflicto entre criollos y americanos y, a lo largo de las décadas, ha mantenido cierta utilidad para varios estudiosos, aunque se le hagan matices. Lo cierto es que la historiografía reciente ha puesto más atención a las transformaciones culturales y políticas que acompañaron el proceso de emancipación que a la independencia misma. En una de las obras más influyentes sobre los procesos revolucionarios hispanoamericanos de comienzos del siglo XIX, François-Xavier Guerra señalaba que la transformación de una cultura política estamental a una moderna se produjo en espacios abiertos por elites modernas, las cuales no eran tanto una clase social cuanto una cultural. ${ }^{48}$ Este cambio de énfasis de lo social a lo cultural y lo político es una de las mayores diferencias entre la historiografía reciente y las propuestas elaboradas por autores como Luis Villoro. Tal vez la clase cultural descrita por Guerra pudiera compararse con la intelligentsia (una clase no vinculada con una clase social, según Mannheim) de La revolución de independencia. No obstante, hay una divergencia sustancial: Villoro siempre se refirió a la intelligentsia criolla, esto es, traicionó (por decirlo de algún modo) su propuesta de explicar las actitudes históricas por los intereses de cada grupo sin importar su lugar de nacimiento. Esto se debe a que para Luis Villoro el tema seguía siendo la emancipación mexicana, mientras que los estudios recientes ponen su atención en el tránsito del orden monárquico al constitucional, un fenómeno

${ }^{48}$ Guerra, Modernidad, 1993, p. 101. compartido por buena parte del mundo atlántico de la época. Si bien la primera edición de $L a$ revolución de independencia admitía la fuerte presencia del liberalismo gaditano en el caso novohispano (incluso como punto de referencia de la Constitución de Apatzingán), todavía era percibido como una "influencia externa" y no como un proceso único. El revisionismo ha terminado por desprenderse del prejuicio nacionalista que impregnaba todavía la historiografía de mediados del siglo Xx. Cada vez son más los trabajos dedicados al análisis de regiones, en los que se pondera la permanencia de una cultura política tradicional al tiempo que se buscaba una mayor autonomía en el marco de la revolución hispánica. ${ }^{49}$

No obstante, queremos destacar que la obra de Villoro, por más discutible que sea, es quizá la única historia general del periodo de la independencia mexicana que se atreve a proponer algo más que una interpretación: un sentido. No es necesario insistir en la falta de trabajos que aborden el proceso de emancipación de un modo completo. Libros como el de Ernesto de la Torre Villar, La independencia de México, o el de Jaime E. Rodríguez O., El proceso de la independencia de México, cumplen con su labor de difusión. ${ }^{50} \mathrm{El}$ primero se inserta en una colección que tiene por objetivo hacer un recuento general de las emancipaciones hispanoamericanas, amén de que la interpretación presentada es por completo la liberal tradicional, sin conceder nada a las nuevas investigaciones. Por el contrario, el de Jaime E. Rodríguez $\mathrm{O}$. es un excelente resumen de las propuestas

\footnotetext{
49 Ávila, "Independencias", 2004, pp. 93-99.

${ }^{50}$ Torre, Independencia, 1992, y Rodríguez, Proceso,
} 1992. 
que en los años recientes varios autores han desarrollado sobre el tema. Por supuesto, rompe con la versión tradicional de la independencia y hace de los letrados y autonomistas el centro de su interpretación.

Es verdad que ha habido también otras obras determinantes para el conocimiento del periodo revolucionario de 1808-1821; pero casi todos esos trabajos tienden a ser monográficos $y$, sobre todo, no corren riesgos con sus conclusiones, no suponen que pueda haber un sentido general para el tema, tal como hizo Villoro. Entendemos que estamos entrando al terreno de discusión de la filosofía de la historia, asunto ya abordado por el mismo autor en otra ocasión. ${ }^{51}$ Por eso mismo, no nos atreveríamos aquí a hacer mayores comentarios sobre esa manera de historiar; pero al menos debemos reconocer que tiene una ventaja: el lector se queda con una idea clara que le permite explicar, sin muchos problemas, el tema abordado, además de insertarlo en una concepción del devenir de la humanidad. Que el sentido otorgado al proceso de la independencia tenga una implicación ideológica es indudable, pero también inevitable $y$, si hemos de concordar con Álvaro Matute, otorga a la monografía una significación de historia plena y no de mero "informe de archivo", según el término empleado por Hayden White. ${ }^{52}$ Por otro lado, no nos parece que Villoro estuviera desencaminado en estudiar las ideologías a partir de las condiciones materiales y experiencias de individuos y grupos. En los últimos años hemos visto

\footnotetext{
5.1 Villoro, "Sentido", 1980.

${ }^{52}$ Matute, "Historia", 1997, p. 5.
}

cómo la historia intelectual se ha beneficiado mucho al dejar de ignorar las condiciones de producción de las ideas. También puede ser muy rescatable la propuesta de Mannheim de acercarse a la mentalidad a través de las maneras de concebir la temporalidad y la historia.. La forma como se imagina el pasado, el presente y el fututo puede ser de enorme utilidad para entender la manera de actuar de las personas, clases o grupos, más allá de las etiquetas tradicionales (independentista, liberal, conservador) . Esto es importante, en especial para los periodos revolucionarios, en los que, como ha señalado Jürgen Habermas, se presenta en los hombres "la convicción de que puede darse un nuevo inicio", de que la historia se construye con las propias manos y no está dada. ${ }^{53} \mathrm{~A}$ partir de la crisis de 1808, los españoles de ambos hemisferios (para emplear una frase de la época) se vieron obligados a actuar para construir su propio futuro, se dieron cuenta, si se nos permite parafrasear a John Pocock, de su propia finitud temporal y enfrentar, de la mejor manera posible, "las embestidas de un flujo de acontecimientos irracionales, concebidos como esencialmente destructivos de todos los sistemas de estabilidad del mundo". ${ }^{54}$ En otras palabras, se percataron de que el orden no estaba dado sino que es producto del arbitrio, de la voluntad y de la actividad del ser humano. La historia les cayó encima. Villoro tuvo muy buen tino al percatarse de esto y puede ser un buen punto de partida para futuras investigaciones del periodo de la emancipación.

\footnotetext{
${ }^{53}$ Habermas, "Soberanía", 1993, p. 32. Véase también Villoro, "Concepto", 1993.

${ }^{54}$ Pocock, Machiavellian, 2003, p. viII.
} 


\section{BIBLIOGRAFIA}

-André, Marius, La fin de l'Empire espagnol d'Amérique, prefacio de Charles Maurras, Nouvelle Librairie Nationale, París, 1922.

-Anna, Timothy E., La caida del gobierno español en la ciudad de México, trad. de Carlos Valdés, FCE, México, 1981.

-Ávila, Alfredo, "De las independencias a la modernidad. Notas sobre un cambio historiográfico" en Erika Pani y Alicia Salmerón (coords.), Conceptualizar lo que se ve. François-Xavier Guerra, bistoriador. Homenaje, Instituto Mora, México, 2004, pp. 76-112.

-Benson, Nettie Lee, La diputación provincial y el liberalismo mexicano, ColmeX, México, 1955. (ed.), Mexico and the Spanish Cortes 1810-1822, University of Texas, Austin, 1966.

-Brading, David A., Orígenes del nacionalismo mexicano, trad. de Soledad Loaeza, Era, México, 1972.

- Mineros y comerciantes en el México borbónico, 1763-1810, trad. de Roberto Gómez Ciriza, FCE, México, 1975.

-Breña, Roberto, "Ideología, ideas y práctica política durante la emancipación de América: panorama del caso novohispano", Historia y política. Ideas, Procesos y Movimientos Sociales, núm. 11, 2004, pp. 9-33.

-Cassirer, Ernst, Filosofía de la Ilustración, versión española de Eugenio Ímaz, FCE, México, 1943.

-Churruca Peláez, Agustín, El pensamiento insurgente de Morelos, pról. de Ernesto de la Torre Villar, Porrúa, México, 1983.

-Florescano, Enrique, Precios del maíz y crisis agricolas en México (1708-1810). Ensayo sobre el movimiento de los precios y sus consecuencias económicas y sociales, Colmex, México, 1969.

-Garrido Asperó, María José, "Por caminos desacostumbrados" en Álvaro Matute y Evelia Trejo (coords.), Escribir la bistoria en el siglo XX: treinta lecturas, UNAM, México, en prensa.
-González y González, Luis, "El optimismo inspirador de la independencia" [1946] en Once ensayos de tema insurgente, El Colegio de Michoacán/Gobierno del Estado de Michoacán, Zamora, 1985, pp. 71-90.

independencia", Historia Mexicana, vol. rv, núm. 13, julio-septiembre de 1954, pp. 124-129.

-Guardino, Peter F., Peasants, Politics, and the Formation of Mexico's National State: Guerrero, 1800-1857, Stanford University, Stanford, 1996.

-Guarisco, Claudia, Los indias del valle de México y la construcción de una nueva sociabilidad politica 1770-1835, El Colegio Mexiquense, Zinacatepec, 2003.

-Guedea, Virginia, "Criollos y peninsulares en 1808. Dos puntos de vista sobre lo español", tesis de licenciatura, Universidad Iberoamericana, México, 1964.

—_. "Los indios voluntarios de Fernando VII", Estudios de Historia Moderna y Contemporánea de México, núm. 10, 1987, pp. 11-83.

—- En busca de un gobierno alterno: los Guadalupes de México, UNAM, México, 1992.

-Guerra, François-Xavier, Modernidade independencia. Ensayos sobre las revoluciones bispánicas, FCE/MAPFre, México, 1993.

-Habermas, Jürgen, "La soberanía popular como procedimiento" en María Herrera (coord.), Jirgen Habermas. Moralidad. Ética y política. Propuestas y críticas, trad. de Ebba Webbels, Alianza, México, 1993.

-Hamill, Hugh, "[Reseña] La revolución de independencia: ensayo de interpretación histórica", Hispanic American Historical Revieu', núm. 34, 1954, pp. 559-560.

-Hamnett, Brian R., Raíces de la insurgencia en México. Historia regional 1750-1824, trad. de Agustín Bárcena, FCE, México, 1990.

-Hernández Luna, Juan, "El mundo intelectual de Hidalgo", Historia Mexicana, vol. 10, núm. 4, octubre-diciembre de 1953, pp. 157-177. 
-Jane, Lionel Cecil, Libertad y despotismo en América Hispana, pról. de Salvador Madariaga, trad. de J. Torroba, Imán, Buenos Aires, 1942.

-Krauze, Enrique, "Luis Villoro, El proceso ideológico de la revolución de independencia", Historia Mexicana, vol. xx, núm. 77, julio-septiembre de 1970, pp. 155-159.

-Lemoine Villicaña, Ernesto, Morelos y la revolución de 1810, UNAM, 3a. ed., México, 1990.

-López Cámara, Francisco, La génesis de la conciencia liberal en México, Colmex, México, 1954.

-Macías, Anna, "Los autores de la Constitución de Apatzingán”, Historia Mexicana, vol. Xx, núm. 4, abril-junio de 1971, pp. 511-521.

- Génesis del gobierno constitucional en México: 1808-1820, trad. de María Elena Hope y Antonieta Sánchez Mejorada de Hope, SEP, México, 1973.

-Mannheim, Karl, Ideology and Utopia. An Introduction to the Sociology of Knowledge, trad. de Louis Writh y Edward Shills, A Harvest Book/ Harcourt, San Diego y Nueva York, 1985.

-Matute, Álvaro, "La historia como ideología", Históricas. Boletín del Instituto de Investigaciones Históricas, núm. 49, mayo-agosto de 1997 , pp. 4-17.

-Méndez Plancarte, Gabriel, Hidalgo. Reformador intelectual, pról. de Ernesto de la Torre Villar, unAM, México, 2003.

-Mier, Servando Teresa de, Escritos y memorias, pról. y selección de Edmundo O'Gorman, UNAM, México, 1945.

- Fray Servando Teresa de Mier, selección, notas y pról. de Edmundo O'Gorman, UNAM, México, 1945.

- Ideario político, edición e introd. de Edmundo O'Gorman, Ayacucho, [Caracas], [1978].

-Miranda, José, Las ideas y las instituciones políticas mexicanas. Primera parte, UNAM, México, 1952.

-Ortega y Medina, Juan A., "El problema de la conciencia cristiana en el padre Hidalgo",
Filosofía y Letras, vol. 24, núms. 47-48, 1952, pp. 193-211.

-Pérez-Marchand, Monelisa Lina, Dos etapas ideológicas del siglo XVIu en México. A través de los papeles de la inquisición, Colmex, México, 1945.

-Pocock, J. A. G., The Machiavellian Moment. Florentine political thought and the Atlantic Republican Tradition, Princeton University, Princeton, 2003.

-Presencia de Rousseau. A los 250 años de su nacimiento y a los dos siglos de la aparición del Emilio $y$ El contrato social, pról. de Mario de la Cueva, UNAM, México, 1962.

-Reyes Heroles, Jesús, El liberalismo mexicano. Los orígenes, UNAM, México, 1957.

-Rodríguez O., Jaime E., El proceso de la independencia de México, Instituto Mora, México, 1992.

, "La transición de colonia a nación:

Nueva España. 1820-1821", Historia Mexicana, vol. XLIIJ, núm. 170 , octubre-diciembre de 1993, pp. 265-322.

—, "De súbditos de la corona a ciudadanos republicanos: el papel de los autonomistas en la independencia de México" en Josefina Zoraida Vázquez (ed.), Interpretaciones de la Independencia de México, Nueva Imagen, México, 1997. pp. 33-69.

- "Rey, religión, yndependencia, y unión": la Independencia de Guadalajara, Instituto Mora, México, 2003.

-Sierra Casasús, Catalina, "Nuevos puntos de vista sobre la independencia", Historia Mexicana, vol. IV, núm. 13, julio-septiembre de 1954 , pp. 129-132.

-Teja Zabre, Alfonso, Historia de México. La independencia, Ediciones Botas, México, 1934.

Aires, 1946. , Morelos, Espasa-Calpe, Buenos

-Torre Villar, Ernesto de la, "Hidalgo y Fleury", Historia Mexicana, vol. II, núm. 10, ocrubrediciembre de 1953, pp. 207-216. 
, La Constitución de Apatzingán y los creadores del Estado mexicano, UNAM, 2a. ed. con un apéndice, México, 1978.

MAPFRE, México, 1992.

-Tutino, John M., From Insurrection to Revolution in Mexico. Social Bases of Agrarian Violence 1750-1940, Princeton University, Princeton, 1986.

-Van Young, Eric, The Other Rebellion. Popular Violence, Ideology, and the Mexican Struggle for Independence 1810-1821, Stanford University, Stanford, 2001.

-Villoro, Luis, "Génesis y proyecto del existencialismo en México", Filosofía y Letras, núm. 36, enero-marzo de 1950, pp. 233-244.

- "Hidalgo: violencia y libertad", Historia Mexicana, vol. II, núm. 2, octubre-diciembre de 1952, pp. 223-239.

, La revolución de independencia. Ensayo de interpretación histórica, Consejo de Humanidades-unam, México, 1953 (Ediciones del Bicentenario del Nacimiento de Hidalgo, 1).

, "Las corrientes ideológicas en la época de la independencia" en Estudios de historia de la filosofía en México, UNAM, México, 1963, pp. 203-242.

- El proceso ideológico de la revolución de independencia, UNAM, México, 1967.

, "El sentido de la historia" en Historia ¿para qué?, Siglo XXI, México, 1980, pp. $35-52$.

- El concepto de ideología y otros ensayos, FCE, México, 1985.

- "Sobre el concepto de revolución", Teoría. Revista de Filosofía, vol. 1, núm. 1, julio de 1993, pp. 69-86.

$\longrightarrow$, El proceso ideológico de la revolución de independencia, CONACULTA, 2a. reimp. de la 3 a. edición, México, 1999 (Cien de México).

- "La revolución de independencia" en Historia general de México. Versión 2000, Colmex, México, 2000, pp. 489-523.

-White, Hayden, Metahistory. The Historical Imagination in Nineteentb-Century Europe, The Johns Hopkins Universiry Press, Baltimore y Londres, 1973.

-Zavala, Silvio, Historia de América, Ricardo Levene (ed.), W. M. Jackson, Buenos Aires, 1940 , vol. vII. 